\title{
POLÍTICA DE EDUCAÇÃO PROFISSIONAL NO BRASIL: ASPECTOS SOCIOECONÔMICOS E IDEOLÓGICOS PARA A IMPLANTAÇÃO DO PRONATEC
}

\author{
Roberto Antonio Deitos* \\ Angela Mara de Barros Lara* \\ IsAura Monica SouZa Zanardini*
}

\begin{abstract}
RESUMO: Este artigo analisa as relaçóes e mediaçóes entre o Estado e a política pública de educação profissional, buscando compreender os argumentos socioeconômicos, político-educacionais e ideológicos para a implantação do Programa Nacional de Acesso ao Ensino Técnico e ao Emprego (Pronatec), criado no governo da presidente Dilma Rousseff, com destaque para o pressuposto de que há maior exigência de qualificação profissional dos jovens e adultos para as ocupaçôes no mercado de trabalho, requeridas pelos setores econômicos diante do contexto das políticas macroeconômicas implementadas no Brasil e da competitividade requerida pela globalização econômica.
\end{abstract}

Palavras-chave: Educação profissional. Pronatec. Qualificação profissional.

\section{PROFESSIONAL EDUCATION POLICIES IN BRAZIL: SOCIOECONOMIC AND IDEOLOGICAL ASPECTS FOR PRONATEC'S IMPLANTATION}

ABSTRACT: This article analyses the relations and mediations between the State and public professional education policies, in order to understand the socioeconomic, political-educational and ideological arguments used to justify the implementation of Pronatec - National Program for Technical Education and Employment Access. This program was created by president Dilma Rousseff's government, based on the assumption that there is a higher demand for professional qualification of adults and young people regarding occupations in the labor market that are required by the socioeconomic sectors in face of the macroeconomic policies which have been implemented in Brazil, and also due to the competitiveness required by economic globalization.

Keywords: Professional Education in Brazil. Pronatec. Professional Qualification.

\footnotetext{
* Universidade Estadual do Oeste do Paraná, Programa de Pós-graduação em Educação. Cascavel, PR., Brasil. E-mail de contato: rdeitos@uol.com.br.

** Universidade Estadual de Maringá, Programa de Pós-graduação em Educação, Maringá, PR., Brasil.
} 


\section{PolitiQue D'EDUCATION PROFESSIONNELlE AU BRESIL: ASPECTS SOCIO-ÉCONOMIQUES ET IDÉOLOGIQUES POUR L'IMPLANTATION DU PRONATEC}

RÉSUMÉ: Cet article analyse les relations et les médiations entre l'État et les politiques publiques d'éducation professionnelle, en cherchant à comprendre les arguments socio-économiques, politiques-éducatifs et idéologiques pour l'implantation du Pronatec - Programme National pour l'Accès à l'Enseignement Technique et à l'Emploi - mis en place dans le gouvernement de la présidente Dilma Rousseff. Il a été fondé sur la présupposition qu'il y a une plus grande demande des compétences professionnelles de la part des jeunes et des adultes pour les professions du marché de travail, requises par les secteurs économiques inséré dans un contexte des politiques macroéconomiques mises en œuvre au Brésil et de compétitivité demandée par la mondialisation économique.

Mots-clés: Enseignement professionnel au Brésil. Pronatec. Qualification professionnelle.

\section{Introdução}

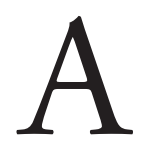

o analisarmos neste artigo alguns aspectos das proposições sociais e educacionais para a política educacional no Brasil e, particularmente, ao Emprego (Pronatec), priorizamos a análise dos argumentos socioeconômicos e político-educacionais apresentados como justificativas teórico-ideológicas para a sua implantação no contexto da política educacional e social brasileira. (ANPED, 2011; AQUINO, 2009; BRASIL, MEC, 2011a; 2011b; 2011c; BRASIL, CONAE, 2010; BRASIL, 2012a; BRASIL, IBGE, 2011)

Buscamos compreender o processo relacional da política educacional como intimamente articulada ao processo de produção socialmente vigente. Assim, um pressuposto básico é examinar como a composição da força de trabalho é chave para compreendermos a funcionalidade da política educacional adotada como uma componente dos suprimentos necessários à profissionalização e aprendizagens impostos pelas demandas do processo produtivo. Ao analisar o processo de divisão manufatureira do trabalho, Marx já retratava o processo de composição da força de trabalho no quadro do processo de produção.

A manufatura cria, portanto, em todo ofício, de que se apossa, uma classe dos chamados trabalhadores náo qualificados, os quais eram rigorosamente excluídos pelo artesanato. Se ela 
desenvolve a especialidade inteiramente unilateralizada, à custa da capacidade total de trabalho, até a virtuosidade, ela já começa também a fazer da falta de todo o desenvolvimento uma especialidade. Ao lado da graduação hierárquica surge a simples separação dos trabalhadores em qualificados e não qualificados. Para os últimos os custos de aprendizagem desaparecem por inteiro, para os primeiros esses custos se reduzem, em comparação com o artesão, devido à função simplificada. Em ambos os casos cai o valor da força de trabalho. [...]. A desvalorização relativa da força de trabalho, que decorre da eliminação ou da redução dos custos de aprendizagem, implica diretamente uma valorizaçáo maior do capital, pois tudo que reduz o tempo de trabalho necessário para reproduzir a força de trabalho amplia os domínios do mais trabalho. (MARX, 1983, p. 276)

O processo de produção da força de trabalho como compósito socioeconômico da sociedade brasileira é o espaço em que vários fatores e aspectos da formação e profissionalização da força de trabalho acabam sendo reproduzidos de forma imediata e mediata. Portanto, desse modo, a política educacional integra o quadro de necessidades formativas que o processo social de produção exige como mediaçóes socioeconômicas. Não é por acaso que o diagnóstico oficial sobre a formação e composição da força de trabalho no Brasil acaba retratando esta questão de maneira direta, assim expressa quando da criação do Pronatec:

Graças a tudo que nós construímos conjuntamente, nos últimos anos, nosso país se encontra diante de uma perspectiva muito importante para cada um de nós, que é a de um vigoroso e duradouro processo de desenvolvimento. Nós passamos a ocupar o posto de $7^{\text {a }}$ economia do mundo, e alcançamos algumas mudanças que, eu tenho certeza, sáo irreversíveis. E os desafios que nós temos de enfrentar, temos a obrigação de enfrentar, eles decorrem justamente dessa característica de termos obtido várias conquistas ao longo desse processo.

Estamos, hoje, próximos do pleno emprego e enfrentamos grande demanda de mão de obra qualificada. Demanda, muitas vezes, assimétrica porque, em alguns casos, falta mão de obra qualificada, em outros, sobra mão de obra sem a qualificação necessária derivada das nossas necessidades, da indústria, do comércio, dos serviços, enfim, do sistema produtivo.

O sistema de capacitação profissional brasileiro já não corresponde às necessidades do país e às dimensôes de nossa economia. Ele é fruto de um outro período do desenvolvimento econômico do nosso país. Por isso, ele se tornou um desafio. Um desafio à nossa capacidade de crescimento e, por isso mesmo, tem de ser enfrentado de maneira direta e muito articulada. 
Nesse sentido, eu lanço hoje aqui o Pronatec, Programa Nacional de Acesso ao Ensino Técnico e ao Emprego. Por um lado, o Pronatec, ele vai democratizar, como o Fernando Haddad, ministro da Educação, mostrou, a oferta de cursos de educaçáo profissional de nível médio. Vai qualificar o nosso nível médio de ensino e elevar a qualidade dessa modalidade de ensino em todo o Brasil. (BRASIL, 2011a)

O presente artigo está organizado com uma introdução que trata dos aspectos gerais que levaram à criação do Pronatec; a segunda parte apresenta um exame dos argumentos socioeconômicos e político-educacionais para a sua implantação e, na terceira parte são apresentadas as consideraçóes finais em que são tratados aspectos teórico-ideológicos para a implantação do programa.

\section{Os argumentos socioeconômicos e político-educacionais para a implantação do Pronatec}

O Pronatec, como programa integrador da política educacional para a educação profissional no país, assume a forma estruturante articuladora nacional no conjunto de açóes educativas e formativas da força de trabalho e, consequentemente, das estratégias viabilizadoras das políticas macroeconômicas adotadas. Neste sentido, as diretrizes governamentais compravam a dinâmica centralizadora e articuladora que assume o Pronatec para o conjunto das políticas adotadas para a educação profissional, como podemos constatar:

Se nós quisermos nos transformar em um país que agrega valor, nós temos de focar na qualidade do nosso trabalhador, seja ele trabalhador com ensino técnico regular derivado das escolas de ensino médio, seja ele um profissional capacitado nos institutos federais de educação tecnológica, seja ele fruto das universidades ou, pura e simplesmente, formado na vida diária do trabalho. Fazê-lo, se transforma no nosso desafio mais importante, quando se trata de discutir a qualidade da Educação. Por isso, nós vamos ampliar a rede de escolas técnicas do governo federal, continuar ampliando aquilo que o presidente Lula, com muito orgulho, dizia: que nós tínhamos conseguido, em oito anos, fazer mais do que ao longo de 100 anos. Nós vamos, além disso, financiar a expansão da rede dos serviços nacionais de aprendizado do Sistema "S", integrado pelo Senai, Senac, Senap, Senar e Sescoop. (BRASIL, 2011a)

É com decisiva determinação governamental que a educação é tomada como requisito indispensável ao processo de produção e desenvolvimento econô- 
mico, e como tal, a política educacional adotada traduz esses objetivos estratégicos e estruturantes em que,

\begin{abstract}
A Educação é reconhecida como um dos principais pilares para o desenvolvimento de uma naçáo, por representar o meio mais eficaz de combate às desigualdades sociais e regionais e de promoçáo do desenvolvimento e do crescimento econômico.

Os três pilares do Plano de Governo se organizavam em torno das três agendas prioritárias: o Programa de Aceleração do Crescimento (PAC), o Plano de Desenvolvimento da Educação (PDE) e a Agenda Social. Por meio dessa agenda de prioridades e do conjunto de programas e açôes, o Governo Federal implementou medidas necessárias para dar continuidade às prioridades de desenvolvimento [...]. (BRASIL. MEC, 2012a, p. 11)
\end{abstract}

O Pronatec, portanto, não significa a exclusão ou a total desorganização de diversos programas, açóes e projetos educativos e formativos em âmbito nacional e estaduais, ao contrário, tornou-se o programa para a política de educação profissional técnica e tecnológica de baixa, média e alta qualificação da força de trabalho no país. Sendo também o integrador político e ideológico e funcional para ancorar o conjunto das açóes, programas e projetos sustentadores da política educacional nacional e regional (estados/municípios). (SHIROMA; LIMA FILHO, 2011; SILVA; AMORIM; VIRIATO, 2011; SAVIANI, 2008; ZANARDINI, I.; LIMA FILHO; SILVA, 2012) Vejamos alguns exemplos institucionais destas premissas:

[...]. Os jovens bem qualificados estâo sendo muito disputados pelas empresas. A economia, [...], é muito dinâmica, e nossa juventude não pode ficar para trás. Por isso mesmo, também queremos ampliar o acesso do jovem ao Ensino Médio de tempo integral. Em um turno, o aluno faz o curso tradicional; no outro, vai aprender uma profissão, vai ter também acesso à cultura e ao esporte. Então, eu quero falar com você que é mãe e pai, também com você que está no finalzinho do Ensino Fundamental: saiba que o governo está investindo na formação da nossa juventude.

\title{
$[\ldots]$
}

Sabe, [...], o mercado de trabalho está oferecendo boas oportunidades e melhores salários para quem tem qualificação. Isso vale para o jovem que sai do Ensino Médio, e para o trabalhador que já está trabalhando ou quer entrar no mercado de trabalho. Hoje, no Brasil, quem tem informação tem emprego. Por isso, no âmbito do Pronatec também ofereceremos formação profis- 
sional, em cursos com carga horária a partir de 160 horas para o trabalhador e a trabalhadora brasileira. (BRASIL, 2011c)

As proposiçóes e justificativas que alimentam a racionalidade e funcionalidade da política educacional sobre os postos de trabalho oferecidos pelo mercado e sobre as possibilidades oferecidas aos jovens e adultos trabalhadores para a qualificação profissional, sustentam que os requisitos educacionais e profissionalizantes são unilateralmente centrais na determinação de ganhos salariais como os de ingresso e permanência nos postos de trabalho. O Gráfico 1 caracteriza a evolução do rendimento médio real do trabalho no país, no período de 2001 a 2011.

\section{Gráfico 1}

Evolução do rendimento médio real do trabalho

(base: set./2011)

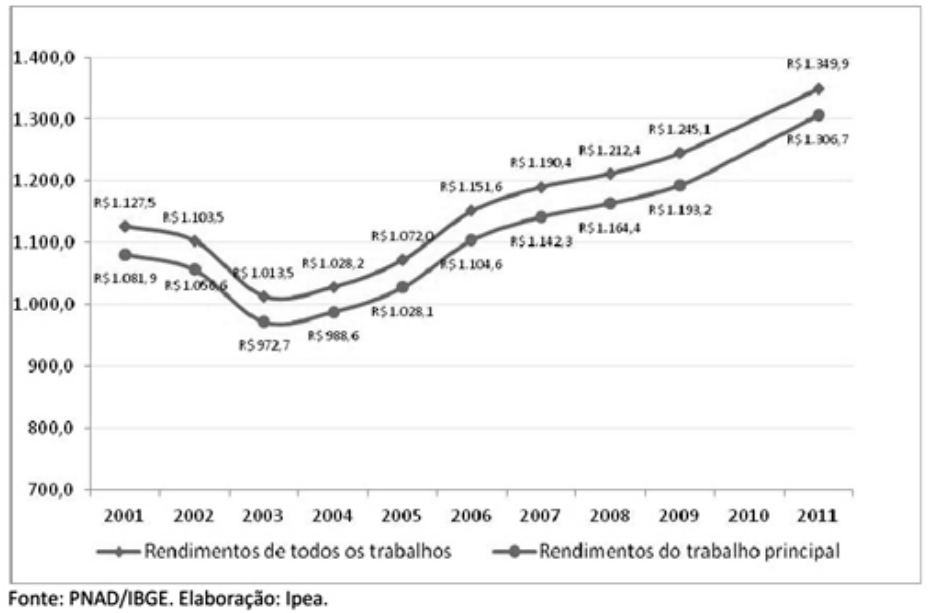

É marcante que o rendimento médio real do trabalho no país obteve relativo aumento, todavia esse aumento relativo médio é baixo considerando-se o processo de desenvolvimento econômico nacional e o resultado relativo da riqueza nacionalmente produzida com o crescimento do Produto Interno Bruto (PIB), neste mesmo período em questão.

Os dados da Tabela 1, representativa da situação salarial em 2001, 2009 e 2011, considerando-se níveis de escolaridade, tipo de atividade econômica principal e características da população ocupada, permite constatar que os rendimentos médios nestas categorias são relativamente baixos no conjunto da 
massa salarial da força de trabalho no país, apesar de relativos crescimentos em determinados grupos analisados.

\section{Tabela 1}

Evolução do rendimento rela médio do trabalho principal por subgrupo ( $\$$ de set./2011)

\begin{tabular}{|c|c|c|c|c|c|c|}
\hline & 2001 & 2009 & 2011 & $\begin{array}{l}\text { Cres. Médio } \\
\text { 01-11 (\% a.a.) }\end{array}$ & $\begin{array}{c}\text { Cres. (\%) } \\
01-11\end{array}$ & $\begin{array}{c}\text { Cres. (\%) } \\
09-11\end{array}$ \\
\hline Brasil & $1.081,90$ & $1.193,20$ & $1.306,70$ & $1,91 \%$ & $20,78 \%$ & $9,51 \%$ \\
\hline \multicolumn{7}{|l|}{ Por Gênero } \\
\hline Homens & $1.228,30$ & $1.355,40$ & $1.463,20$ & $1,77 \%$ & $19,13 \%$ & $7,96 \%$ \\
\hline Mulheres & 852,10 & 966,50 & $1.086,20$ & $2,46 \%$ & $27,48 \%$ & $12,38 \%$ \\
\hline \multicolumn{7}{|l|}{ Por Cor/Raça } \\
\hline Brancos & $1.406,30$ & $1.527,20$ & $1.650,20$ & $1,61 \%$ & $17,34 \%$ & $8,05 \%$ \\
\hline Pretos & 716,30 & 877,70 & 964,00 & $3,01 \%$ & $34,58 \%$ & $9,82 \%$ \\
\hline Pardos & 736,80 & 905,10 & $1.013,50$ & $3,24 \%$ & $37,56 \%$ & $11,98 \%$ \\
\hline \multicolumn{7}{|l|}{ Por idade } \\
\hline 15 a 24 anos & 521,30 & 613,50 & 696,20 & $2,94 \%$ & $33,55 \%$ & $13,47 \%$ \\
\hline 25 a 49 anos & $1.197,60$ & $1.244,50$ & $1.351,40$ & $1,22 \%$ & $12,84 \%$ & $8,59 \%$ \\
\hline 50 ou mais de idade & $1.327,90$ & $1.515,00$ & $1.641,90$ & $2,15 \%$ & $23,65 \%$ & $8,38 \%$ \\
\hline \multicolumn{7}{|l|}{ Por Escolaridade } \\
\hline 0 a 3 anos & 483,90 & 565,30 & 671,20 & $3,33 \%$ & $38,70 \%$ & $18,74 \%$ \\
\hline 4 a 7 anos & 693,90 & 741,40 & 843,70 & $1,97 \%$ & $21,59 \%$ & $13,80 \%$ \\
\hline 8 a 10 anos & 860,20 & 827,90 & 913,70 & $0,61 \%$ & $6,22 \%$ & $10,36 \%$ \\
\hline 11 ou mais & $1.970,70$ & $1.738,80$ & $1.806,20$ & $-0,87 \%$ & $-8,35 \%$ & $3,87 \%$ \\
\hline \multicolumn{7}{|l|}{ Por Atividade } \\
\hline Agrícola & 575,00 & 700,10 & 808,60 & $3,47 \%$ & $40,62 \%$ & $15,49 \%$ \\
\hline Indústria & $1.084,40$ & $1.195,60$ & $1.278,10$ & $1,66 \%$ & $17,86 \%$ & $6,90 \%$ \\
\hline Construção & 836,50 & 967,20 & $1.094,70$ & $2,73 \%$ & $30,87 \%$ & $13,18 \%$ \\
\hline Comércio & $1.109,90$ & $1.069,30$ & $1.167,20$ & $0,50 \%$ & $5,16 \%$ & $9,16 \%$ \\
\hline Serviços & 998,60 & $1.110,00$ & $1.227,70$ & $2,09 \%$ & $22,94 \%$ & $10,60 \%$ \\
\hline Administração Pública & $2.008,10$ & $2.373,50$ & $2.408,70$ & $1,84 \%$ & $19,95 \%$ & $1,48 \%$ \\
\hline \multicolumn{7}{|l|}{ Por Ocupação } \\
\hline Com carteira & $1.109,40$ & $1.173,50$ & $1.230,40$ & $1,04 \%$ & $10,91 \%$ & $4,85 \%$ \\
\hline Sem carteira & 570,60 & 642,80 & 736,00 & $2,58 \%$ & $28,98 \%$ & $14,49 \%$ \\
\hline Conta própria & 903,20 & 918,10 & $1.148,20$ & $2,43 \%$ & $27,13 \%$ & $25,07 \%$ \\
\hline Empregador & $3.540,80$ & $3.543,00$ & $4.102,70$ & $1,48 \%$ & $15,87 \%$ & $15,80 \%$ \\
\hline Funcionário Público & $1.932,90$ & $2.341,30$ & $2.461,50$ & $2,45 \%$ & $27,35 \%$ & $5,13 \%$ \\
\hline \multicolumn{7}{|l|}{ Por Região } \\
\hline Norte & 969,50 & $1.065,30$ & $1.170,30$ & $1,90 \%$ & $20,71 \%$ & $9,86 \%$ \\
\hline Nordeste & 734,50 & 848,80 & 940,90 & $2,51 \%$ & $28,10 \%$ & $10,85 \%$ \\
\hline Centro-oeste & $1.277,30$ & $1.512,70$ & $1.637,40$ & $2,51 \%$ & $28,19 \%$ & $8,24 \%$ \\
\hline Sudeste & $1.280,00$ & $1.326,70$ & $1.454,10$ & $1,28 \%$ & $13,60 \%$ & $9,64 \%$ \\
\hline Sul & $1.225,00$ & $1.382,30$ & $1.456,50$ & $1,75 \%$ & $18,90 \%$ & $5,37 \%$ \\
\hline
\end{tabular}

Fonte: Pnad/IBGE. Elaboração: Ipea.

Fonte: BRASIL. IPEA, $2012 b$. 
Os dados apresentados no Gráfico 2 demonstram algumas características em que o processo de produção acaba gerando a redução da média geral da força de trabalho, considerando ainda que houve uma evolução dos anos de estudo do conjunto da população, que integra o volume da força de trabalho ocupada no país.

\section{Gráfico 2}

Evolução do rendimento por anos de escolaridade

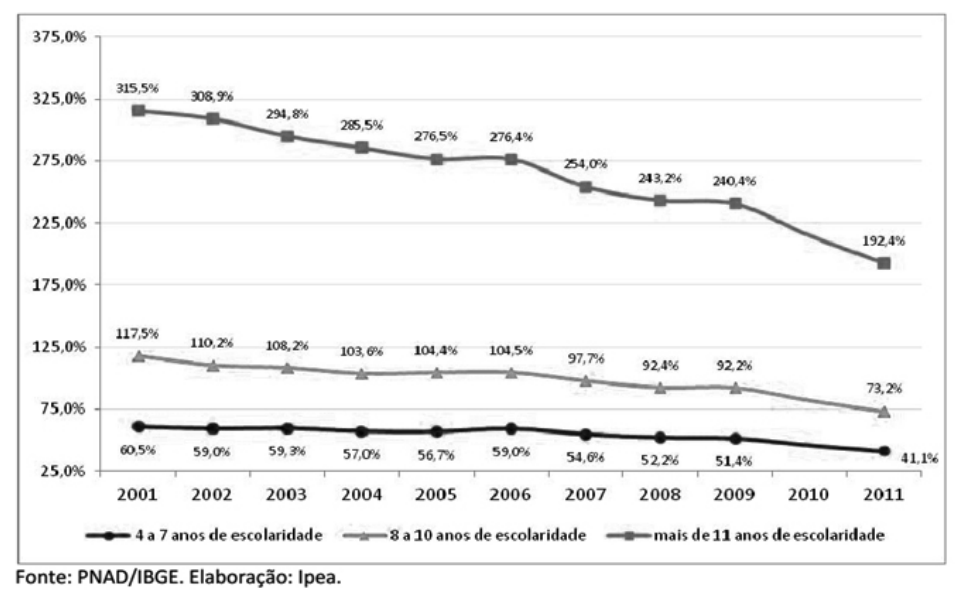

Fonte: BRASIL. IPEA, 20126.

Os motivos socioeconômicos e políticos e as razões teórico-ideológicas e educacionais para justificar as políticas educacionais implementadas no país de que "[...] o mercado de trabalho está oferecendo boas oportunidades e melhores salários para quem tem qualificação [...]” (BRASIL, 2011c), apresenta forte dispositivo de internalização psicossocial e ideológico para a manutenção de uma política educacional voltada para a formação da força de trabalho e alinhada sob a tutela dos interesses econômicos e políticos hegemônicos nacionais. Apenas examinando-se os dados do Gráfico 2 se percebe que os anos de estudo da força de trabalho disponível vem crescendo relativamente no país, ao mesmo tempo em que a evolução do rendimento nos níveis de mais anos de estudo vai caindo em proporção relativamente alta. Esse dado por si só já é a confirmação latente de que inversamente ao aumento dos anos de estudo (escolaridade da força de trabalho) a evolução dos rendimentos sofre queda. Outro dado do DIEESE (2011a, p. 67) reafirma a situação da queda na evolução da remuneração por escolaridade, como pode ser observado na distribuição da população de jovens ocupados em empregos formais de 16 a 29 anos, conforme Tabela 2. 


\section{Tabela 2}

Distribuição dos empregos formais dos jovens de 16 a 29 anos, por faixas de remuneração, segundo escolaridade Brasil 2010 (em \%)

\begin{tabular}{l|c|c|c|c|c}
\hline Escolaridade & Até 1 SM & Mais de 1 a 2 SM & Mais de 2 SM & Total & $\begin{array}{c}\text { Total } \\
\text { (em nos abs.) }\end{array}$ \\
\hline Sem instrução & 20,0 & 67,3 & 12,7 & 100,0 & 27.796 \\
\hline Fundamental incompleto & 12,0 & 68,7 & 19,3 & 100,0 & 1.449 .946 \\
\hline Fundamental completo & 8,5 & 67,4 & 24,1 & 100,0 & 1.648 .170 \\
\hline Médio incompleto & 15,0 & 65,8 & 19,2 & 100,0 & 1.699 .966 \\
\hline Médio completo & 7,1 & 61,9 & 31,0 & 100,0 & 7.925 .603 \\
\hline Superior incompleto & 4,6 & 39,9 & 55,5 & 100,0 & 934.743 \\
\hline Superior completo & 3,8 & 19,3 & 76,8 & 100,0 & 1.445 .285 \\
\hline TOTAL & 8,2 & 58,2 & 33,7 & 100,0 & 15.131 .509 \\
\hline
\end{tabular}

Eonte: MTE.Rais

Elaboraçăo: DIEESE

ta: (1) Refere-se a remuneração média em dezembro

(2) Inclui mestrado e doutorado
(3) Exclui os registros sem infomação de remuneraçăo

Fonte: DIEESE, $2011 b$.

A distribuição de jovens brasileiros apresenta grande volume em todos os níveis de escolaridade de rendimento de até 2 salários, correspondendo a $66,4 \%$ do total de jovens em empregos formais em 2010.

Contraditoriamente, o processo de produção requer níveis de qualificação por ocupação que vão de forma relativa de encontro com os níveis de escolarização (BRASIL. IPEA, 2012, p. 19), requeridos pelos setores econômicos, como podemos observar com relação aos dados apresentados no Gráfico 3.

\section{Gráfico 3}

Distribuição por nível de qualificação exigido pela ocupação ${ }^{1}$

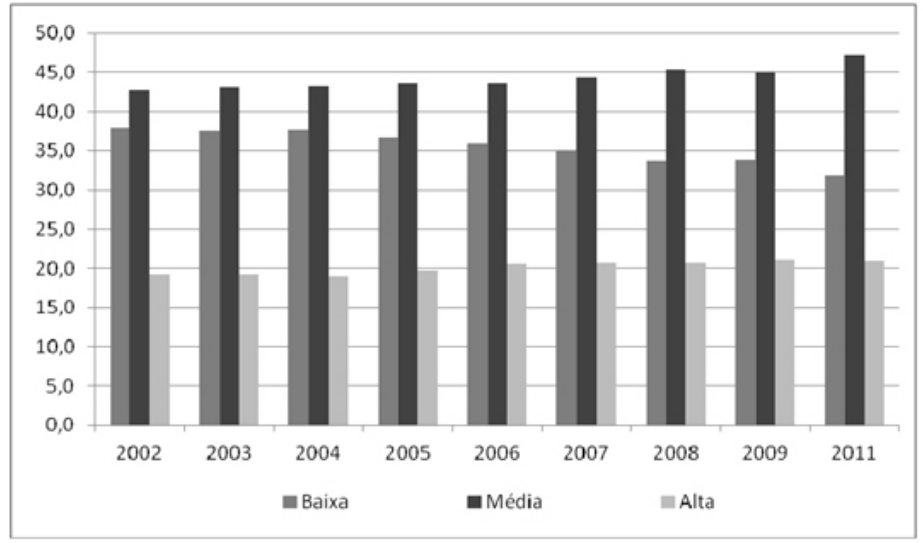

Fonte: PNAD/IBGE. Elaboração: Ipea. 
Os dados do Gráfico 3 (BRASIL, IPEA, 2012, p. 22,) revelam que a distribuição de ocupação por nível de qualificação alta subiu apenas 2 pontos percentuais de 2002 a 2011. Já a distribuição de ocupação por nível de qualificação média cresceu em torno de 4 pontos percentuais no mesmo período; o que também não é muito elevado. E, por fim, a distribuição de ocupação por nível de qualificação baixa caiu 6 pontos percentuais neste mesmo período analisado. Mesmo com o aumento relativo dos anos de estudo dos trabalhadores nos últimos 10 anos, pode-se constar que o aumento da escolarização não é o principal processo de exigência para as ocupaçôes, mas requisitos para o processo de pressão e seleção da quantidade de força de trabalho necessária; tanto que $79 \%$ da distribuição por nível de qualificação exigido pela ocupação estão centrados nos níveis de baixa e média qualificação.

Aumenta, portanto, a condição do capital na proporção do aumento do volume da força de trabalho com mais anos de estudo ou escolaridade para pressionar a massa salarial para baixo, possibilitando maior produtividade na outra ponta do processo ao reduzir custos da força de trabalho pelo mecanismo de requerimentos de níveis mais elevados de escolarização. Um exemplo deste feito, no que se refere ao processo de requerimentos de qualificação alta, que abarca em torno de $20 \%$ dos postos ocupados nos setores produtivos da economia brasileira (BRASIL, IPEA, 2012, p. 22); qualificações estas, conforme observamos no Gráfico 3 com queda na evolução dos rendimentos ocupados.

No campo educacional, o volume de cursos de profissionalização inicial e continuada e cursos técnicos de nível médio no conjunto das ofertas nacionais e estaduais no Brasil, atendem a todos os setores de atividades econômicas e respondem funcional e ideologicamente pelos requerimentos destes mesmos setores quanto ao volume da força de trabalho e que possa atender aos aspectos qualitativos imediatos e mediatos para a formação da força de trabalho necessária e disponível demanda pelo empresariado. A capacidade operacional e financeira de sustentabilidade estatal com o desenvolvimento da política nacional de educação profissional pode ser constatada no Gráfico 4.

Ocorreu um forte crescimento nos investimentos públicos nos programas, açóes e treinamentos no campo da educação profissional em nível da qualificação inicial e continuada, dos cursos técnicos e tecnológicos. Os valores orçamentários executados de 2006 a 2011 nos dão a dimensão dos recursos públicos envolvidos, de um patamar de 1,5 bilhóes em 2006 para atingir quase 6 bilhôes de reais em 2011. 


\section{Gráfico $4^{2}$}

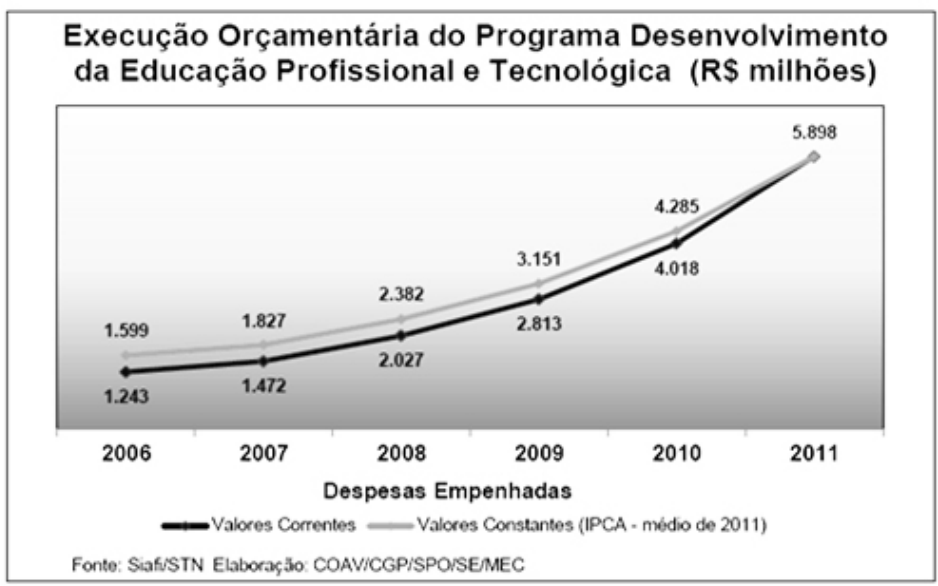

Dados preliminares mais recentes dão conta que os recursos dirigidos para sustentar as metas previstas na política pública de educacional profissional, tendo no Pronatec sua estratégia central de articulação com os setores privados em todos os ramos da economia, são muito superiores aos destinados até 2011, ano de criação do Pronatec, de acordo com dados publicados em nota pública encaminhada ao Ministério da Educação pelos pesquisadores reunidos no II Colóquio Nacional A Produção do Conhecimento em Educação Profissional, realizado em 2013, os valores previstos para a política de educação profissional "São 24 bilhôes de reais (BRASIL, 2012) cuja maior parte destina-se ao sistema 'S', inclusive, para financiar a 'expansão da rede física de atendimento dos serviços nacionais de aprendizagem'[...]". (IFRN, 2013)

\section{Considerações finais}

Os argumentos teórico-ideológicos e educacionais que alimentam os fundamentos socioeconômicos e políticos do arcabouço programático que sustenta o receituário governamental e empresarial para a implementação de reformas da política pública de educação profissional vem sendo disseminado de longa data, particularmente com ênfase a partir da década de 1990.

Una fuerza de trabajo competente y flexible, capaz de adquirir nuevos conocimientos a medida que las economías cambian, es un requisito necesario para el desarrollo económico y social. La sociedad se beneficia a través de una mayor productividad y de 
la capacidad para adaptarse a circunstancias y oportunidades económicas cambiantes, y los individuos se benefician a través de mayores ingresos y del aumento de la movilidad para buscar mejores oportunidades de empleo. (BANCO MUNDIAL, 1992, p. 21)

Sem fugir dos propósitos econômicos e ideológicos, a visão recente de destacado empresário brasileiro (detentor de uma das maiores fortunas mundiais), ao falar de questóes econômicas, de produtividade das empresas, em reunião realizada no Palácio do Planalto, convergente com as análises do Banco Mundial, manifestava de forma mais direta e precisa a visão empresarial sobre as demandas por pessoal qualificado:

Eu acho que, para a economia crescer, evoluir como eu espero que ela vai evoluir, você tem que ter mão de obra qualificada. Contratar pessoas qualificadas no Brasil está caríssimo no momento, há uma demanda grande e pouca oferta. Então, eu acho que nós temos que melhorar nesse sentido. (LEMANN, 2013)

Todo o eixo econômico, político e ideológico do discurso do empresariado, aqui manifestado organicamente por um dos seus líderes, se articula ao discurso governamental, representado pelo Estado brasileiro e suas unidades federativas, como o conjunto de instituições jurídico-estatais e administrativas, é uma clara definição da funcionalidade que deve ocupar a política educacional nacional e regional na composição e reprodução da força de trabalho brasileira. Historicamente no Brasil, os setores econômicos e o empresariado hegemônico sempre transferiram os custos da escolarização e qualificação da força de trabalho para o Estado brasileiro no conjunto das políticas públicas. (XAVIER; DEITOS, 2006; DEITOS, 2000; 2003; 2005; 2006; 2008; 2010; 2012a; DEITOS et al, 2012; LIMA FILHO; SILVA; DEITOS, 2011) Por isso que:

[...]. A contínua expansão do sistema educativo tornar-se-ia - em relação à base do poder político de seus protagonistas - demasiado cara, sobretudo se ele diminui a força de convencimento da autojustificação para o trabalho economicamente produtivo. Da perspectiva do capitalista individual, um sistema educacional que não tem mais em vista a qualificação de uma capacidade de trabalho economicamente utilizável como seu tema exclusivo e que claramente fracassa, além disso, no preenchimento de sua função geral de integração, aparece mais ou menos como uma instituição parasitária de custos muito elevados sem retorno [...].

(OFFE, 1990, p. 52-53) 
A política pública de educação profissional, ancorada estratégica e ideologicamente no Pronatec, está visivelmente atravessada pelo compósito de mediaçóes de um processo com características peculiares e particulares, mas que não rompe com o arcabouço estruturante que condiciona a política educacional implementada no período de 2003 a 2013, cumprindo a funçáo integradora e articuladora dos interesses socioeconômicos e políticos regionais socioeconômicos articulados organicamente com os interesses nacionais e internacionais da globalização econômica. (MÉSZÁROS, 2002) Esta mesma política é, sem dúvida, o alimentador teórico-ideológico e político-funcional da articulação macroinstitucional-econômica e microeconômica-político-institucional regional (estados/municípios; empresas/setores econômicos/trabalhadores) da parceria público-privada de desenvolvimento da política pública de educação profissional no país e nas unidades federativas e suas respectivas localidades municipais, além do fomento às instituiçóes privadas, setores estes que hegemonizam os recursos e a direção teórica e funcional do processo e expansão da oferta e conteúdos requeridos, pela educação profissional, em cursos e treinamentos básicos e nos cursos de nível médio e técnico profissional, como também daqueles em nível tecnológico em instituiçóes públicas e privadas no âmbito do ensino superior.

Os fundamentos socioeconômicos e políticos, teórico-ideológicos e educacionais da política educacional, nessa direção, produzem vertiginoso discurso governamental, empresarial e funcional de que a ineficiência funcional e profissionalizante, de jovens e adultos trabalhadores, é mecanismo requerido pela dinâmica econômica, ao mesmo tempo em que leva os próprios trabalhadores a assumir (internalizar) como condição individualizada para a sua desqualificação/escolarização/qualificação, que acaba sendo reforçada e adotada como uma condição unilateral para o seu ingresso e permanência no processo produtivo (emprego e empregabilidade), e para a sua própria manutenção como força de trabalho, gerando internamente (nos indivíduos) as condiçóes de aceitabilidade de expectativas sociais de desempenho escolar, qualificação e empregabilidade como condição unilateral à conquista de emprego no contexto econômico produtivo nacional. (ZANARDINI, 2008; CASTRO, 2000; BRASIL. MEC, 2012c; BRASIL. MEC, 2012d; BRASIL. MEC, 2012e; BRASIL. MEC, 2012f) Com isso reforça-se o discurso ideológico da manutenção das exigências produtivas e políticas como promotoras de viabilidades psicossociais e de produção que permite aos jovens e adultos desempregados internalizar que a causa de sua situação social ou da necessidade de manutenção em seus postos de trabalho só podem ser acessados ou mantidos se o processo de escolarização ou qualificação/profissionalização for permanentemente mantido e ampliado, como fator de enfrentamento da expansão da produtividade e da tecnologia adotadas no processo de produção, como sendo esta expansáo a viabilizadora de emprego ou a geradora de supostas e novas competências e qualificaçóes para o acesso aos mesmos, como sendo os novos modernos empregos gerados pelo chamado novo desenvolvimentismo 
(MERCADANTE-OLIVA, 2010; BRESSER-PEREIRA, 2011) característico da competitividade econômica produzida pela globalização do capital.

\section{Notas}

1. Nota do autor no original: Nota 6, p. 21, Autor, D. U.S. Labor Market Challenges over the Longer Term. Federal Reserve Board of Governors Consultant Paper, October 2010. Foram classificados como altamente qualificados os dirigentes, profissionais das ciências e das artes e técnicos de nível médio. No grupo de qualificação média foram incluídos os trabalhadores de serviços administrativos (escriturários e de atendimento), os vendedores e os trabalhadores da produçáo. Como pouco qualificados foram classificados os trabalhadores dos serviços (domésticos, de transportes, segurança, administração de edifícios, saúde, embelezamento, entre outros) e os agrícolas.

2. Nota no original: A evolução dos índices apresenta na tabela passou por uma revisão dos cálculos realizados sobre a base primária do Inep, sendo considerados as três modalidades de matrículas no ensino profissional: concomitante, subsequente e integrada. Como não houve revisão do PPA, não foi possível modificar os valores no SIGPlan, por isso a divergência em relação às Avaliaçóes de Programa realizadas nos anos anteriores.

\section{Referências}

ANPEd. ASSOCIAÇÃO NACIONAL DE PÓS-GRADUAÇÃO E PESQUISA EM EDUCAÇÃO. Por um Plano Nacional de Educação (2011-2020) como política de Estado. Rio de Janeiro: ANPED, 2011.

AQUINO, L. M. C. de. A juventude como foco das políticas públicas (Introdução). In: CASTRO, J. A. de; AQUINO, L. M. C. de; ANDRADE, C. C. de. Juventude e políticas sociais no Brasil. Brasília, DF: IPEA, 2009.

BANCO MUNDIAL. Educación técnica y formación profesional. Washington, D.C.: Banco Mundial, 1992. [Primera edición en inglés mayo de 1992; primera edición en español, abril de 1992].

BRASIL. Lei No 12.513, de 26 de outubro de 2011. Institui o Programa Nacional de Acesso ao Ensino Técnico e Emprego (Pronatec). Brasília, DF., Diário Oficial da Uniáo, 27 out. 2011a.

. Resumo técnico - Censo escolar 2010. Brasília, DF.: INEP, 2011 b.

. Programa de rádio "Café com a Presidenta", com a Presidenta da República, Dilma

Rousseff. Rádio Nacional. Brasília, DF., 14 de fevereiro de 2011c.

. IBGE. Sinopse do Censo Demográfico 2010. Rio de Janeiro: IBGE, 2011.

. IPEA. Situação social nos estados - Paraná. Brasília: IPEA, 2012, p. 27, Gráfico 19.

. MEC. Relatório de Avaliação - plano plurianual - 2008-2011. (Avaliação Setorial.

Exercício 2012. Ano base 2011). Brasília: MEC, 2012a. 
BRASIL. IPEA. PNAD 2011: Primeiras Análises sobre o Mercado de Trabalho Brasileiro. Comunicados do Ipea, n. 156. Brasília, DF.: IPEA, 2012b. Disponível em: <http://www. ipea.gov.br>.

2010

. MEC. CONAE 2010 - Conferência Nacional de Educação. Brasília, DF: CONAE,

MEC. Diretrizes Curriculares Nacionais para a Educação Profissional Técnica de Nivel Médio. Brasília: MEC/SETEC/CNE/CEB, 2012c, p. 41-42.

. MEC. Sistema Nacional de Informaçóes da Educação Profissional e Tecnológica. Brasília: MEC, SISTEC, 2012d. Disponível: <http://sitesistec.mec.gov.br/index. php?option=com content $\&$ view $=$ article $\&$ id $=255:$ resultado $\&$ catid=42:resultados $\&$ Item $\underline{\mathrm{id}=217}$ > . Acesso em março de 2013.

. MEC. Catálogo Nacional de Cursos - Edição 2012. Brasília, DF: MEC, SETEC, 2012 e.

. MEC. Guia PRONATEC de cursos FIC - Programa nacional de acesso ao ensino técnico e emprego. Brasília, DF: MEC, SETEC, PDE, $2012 \mathrm{f}$.

BRESSER-PEREIRA, L. C. O Brasil e o Novo Desenvolvimentismo. Interesse Nacional. abril/jul. 2011. Disponível em: <http://www.bresserpereira.org.br/Papers/2011/10.26a. Brasil Novodesenvolvimentismo InteresseNacional.pdf>. Acesso em 20 set. 2013.

CASTRO, C. de M. et al. Reforma de la educación primaria y secundaria en América Latina y el Caribe. Washington, D.C.: Banco Interamericano de Desarrollo. marzo-junio de 2000. (Serie de informes de políticas y estrategias sectoriales del Departamento de Desarrollo Sostenible).

COLÓQUIO NACIONAL A PRODUÇÃO DO CONHECIMENTO EM EDUCAÇÃO PROFISSIONAL, 2., 2013. Rio Grande do Norte. Anais... Rio Grande do Norte: Programa de Pós-graduação em Educação Profissional. Instituto Federal de Educação Ciência e Tecnologia do Rio Grande do Norte, 2013. Disponível em: <http://www2.ifrn. edu.br/coloquioeducacao2013>.

DEITOS, R. A. Ensino médio e profissional e seus vínculos com o BID/BRID: os motivos e as razóes ideológicas da política educacional. Cascavel: EDUNIOESTE, 2000.

A política educacional paranaense para o ensino médio e profissional (19952002): o PROEM e as recomendaçóes do BID e Banco Mundial. In: NOGUEIRA, F. M. G.; RIZZOTTO, M. L. F. (Orgs.). et al. Estado e politicas sociais: Brasil-Paraná. Cascavel, PR: Edunioeste, 2003.

O capital financeiro e a educaçáo no Brasil. 2005. Tese (Doutorado em Educação) - Faculdade de Educação. Universidade Estadual de Campinas - UNICAMP, 2005.

. História da política educacional paranaense para o ensino médio e profissional (1995-2002). In: SEMINÁRIO NACIONAL HISTEDBR. 7., 2006, Campinas, SP. Anais... FE/Unicamp: Histedbr, 2006. 
DEITOS, R. A. Liberalismo educacional: o receituário de Milton Friedman. In: ZANARDINI, I. M. S.; ORSO, P. J. (Orgs.). Estado, educaçâo e sociedade capitalista. Cascavel: Edunioeste, 2008. p. 25-38.

. Políticas públicas e educação: aspectos teórico-ideológicos e socioeconômicos. Acta Scientiarum. Education, v. 32, n. 2, p. 209-218, 2010.

. O liberalismo social-democrata e a reforma do Estado brasileiro (1995-2002). Perspectiva. Revista do Centro de Ciências da Educação, v. 30, n. 1, p. 199-229, jan./abr. 2012.

. Estado e política pública de educação profissional: os motivos socioeconômicos e políticos e as razóes educacionais e teórico-ideológicas da política educacional paranaense. In: SEMINÁRIO DE PESQUISA DO PROGRAMA DE PÓS-GRADUAÇÃO EM EDUCAÇÃO, 11., 2012, Maringá, PR. Anais... Maringá: Eduem, 2012b. v.1. p.1-13.

et al. O PROEJA como política pública: aspectos socioeducacionais, políticos e institucionais. In: ZANARDINI, I. M. S.; LIMA FILHO, D. L.; SILVA, M. R. da (Orgs.). Produção do Conhecimento no PROEJA: cinco anos de pesquisa. Curitiba, PR: Ed. UTFPR, 2012, p. 77.

DEITOS, R. A.; LARA, A. M. de B. Estado e política pública de educação profissional: os motivos socioeconômicos e políticos e as razôes educacionais e teórico-ideológicas da política educacional paranaense. Imagens da Educação, v. 2, n. 2, p. 75-86, 2012.

DIEESE. Qualificação e Mercado de Trabalho: Apontamentos para política pública em regióes metropolitanas. Pesquisa DIEESE, São Paulo, n. 18, dez. 2011a.

. Anuário do Sistema Público de Emprego, Trabalho e Renda 2010/2011: juventude.

3. ed., Departamento Intersindical de Estatística e Estudos Socioeconômicos. Sáo Paulo: DIEESE, 2011b. 100 p. (Juventude, 6).

LEMANN, J. P. Discurso. Governo passa a exigir cota de participação nacional no PAC. $80 \%$ dos gastos em mobilidade devem ser com produtos nacionais. Equipamentos também tem que ter alguma fase de produção no Brasil. Jornal O Globo. Brasília, 16 de janeiro de 2013. Disponível em: <http://g1.globo.com/jornal-da-globo/noticia/2013/01/ governo-passa-exigir-cota-de-participacao-nacional-no-pac.html $>$. Acesso em março de 2013.

LIMA FILHO, D. L., SILVA, M. R., DEITOS, R. A. (Orgs.). PROEJA - educação profissional integrada à EJA: questôes políticas, pedagógicas e epistemológicas. Curitiba, PR: Ed. UTFPR, 2011.

MARX, K. O capital. Critica da economia política. Volume I, Livro primeiro. O processo de produção do capital. Tomo 1, (Prefácios e Capítulos I a XII). Apresentação Jacob Gorender. Coordenação e revisão de Paul Singer. Tradução de Regis Barbosa e Flávio R. Kothe. São Paulo: Abril Cultural, 1983.

MERCADANTE-OLIVA, A. As Bases do Novo Desenvolvimentismo no Brasil: Análise do governo Lula (2003-2010). 2010. Tese (Doutorado em Ciências Econômicas). Universidade Estadual de Campinas, Campinas, SP. 2010. Disponível em: $<\underline{\text { http://www. }}$ bibliotecadigital.unicamp.br/document/?code=000794314 >. Acesso em 10 jul. 2013. 
MÉSZÁROS, I. Para além do capital - rumo a uma teoria da transição. São Paulo: Boitempo Editoral; Campinas, SP: Editora da Unicamp, 2002.

OFFE, C. Sistema Educacional, sistema ocupacional e política da educação - contribuição à determinação das funçôes sociais do sistema educacional. Educ. Soc., n. 35, Campinas, 1990, p. 40-41.

SAVIANI, D. Sistema nacional de educação: conceito, papel histórico e obstáculos para sua construção no Brasil. In: REUNIĀO ANUAL DA ANPED, 31., 2008, Caxambu. Anais... Caxambu: ANPED, 2008.

SILVA, M. R.; AMORIM, M. L., VIRIATO, E. O. (Orgs.). PROEJA - educação profissional integrada à EJA: entre políticas e práticas. Curitiba: Ed. UTFPR, 2011, p. 13-31.

SHIROMA, E. O.; LIMA FILHO, D. L. Trabalho docente na educação profissional e tecnológica e no PROEJA. Educ. Soc., Campinas, v. 32, n. 116, p. 725-743, jul./set. 2011, p. $727-728$.

XAVIER, M. E. S. P., DEITOS, R. A. Estado e Política Educacional no Brasil. In.: DEITOS, R.A; RODRIGUES, R.M. (Orgs.). Estado, desenvolvimento, democracia e políticas sociais. Cascavel: Edunioste, 2006.

ZANARDINI, I. M. S.; LIMA FILHO, D. L.; SILVA, M. R. da (Orgs.). Produção do Conhecimento no PROEJA: cinco anos de pesquisa. Curitiba: Ed. UTFPR, 2012.

ZANARDINI, J. B. Ontologia e avaliaçáo da educaçáo básica no Brasil (1990-2007). 2008. Tese (Doutorado em Educação) - Universidade Federal de Santa Catarina, Florianópolis, 2008, p. 121-155.

Recebido em 23 de fevereiro de 2015.

Aprovado em 23 de outubro de 2015.

DOI: http://dx.doi.org/10.1590/ES0101-73302015132445 